\title{
False recognition in younger and older adults: Exploring the characteristics of illusory memories
}

\author{
KENNETH A. NORMAN and DANIEL L. SCHACTER \\ Harvard University, Cambridge, Massachusetts
}

\begin{abstract}
Roediger and McDermott (1995) demonstrated that when subjects hear a list of associates to a "theme word" that has itself not been presented, they frequently claim to recollect having heard the nonpresented theme word on the study list. In Experiment 1, we found that asking subjects to explain their remember responses, by writing down exactly what they remembered about the item's presentation at study, did not significantly diminish the rate of remember false alarms to nonpresented theme words. We also found that older adults were relatively more susceptible than younger adults to this false-recognition effect. Subjects' explanations suggested that both veridical and illusory memories were predominantly composed of associative information as opposed to sensory and contextual detail. In Experiment 2, we obtained quantitative evidence for this conclusion, using a paradigm in which subjects were asked focused questions about the contents of their recollective experience. Lastly, we found that both younger and older adults recalled more sensory and contextual detail in conjunction with studied items than with nonpresented theme words, although these differences were less pronounced in older adults.
\end{abstract}

Memory is often accurate, but under certain conditions memory distortions and illusions can occur (for reviews, see Roediger, 1996; Schacter, 1995, 1996). Beginning with F. C. Bartlett (1932), cognitive psychologists have delineated conditions in which people claim to remember words or sentences that were never presented (e.g., Bransford \& Franks, 1971; Sulin \& Dooling, 1974; Underwood, 1965), recall details of events that were implanted by suggestive questioning (Loftus, Miller, \& Burns, 1978; Zaragoza \& Lane, 1994), recollect seeing things that they only imagined (Garry, Manning, Loftus, \& Sherman, 1996; Johnson, Raye, Wang, \& Taylor, 1979), and describe events that never occurred (Hyman, Husband, \& Billings, 1995; Loftus \& Pickrell, 1995).

For the most part, the memory distortions observed in laboratory studies constitute modest effects, with false recall and recognition occurring relatively infrequently. Roediger and McDermott (1995; see also Read, 1996) have recently reported a false-recognition effect that is striking because it can be readily elicited with high frequency and is accompanied by a strong subjective feeling of remembering. Roediger and McDermott revived and modified a paradigm, introduced originally by Deese (1959), in which subjects hear a series of lists; each list is composed of associates to a single nonpresented "theme

Preparation of this article was supported by National Institute on Aging Grant AG08441-06, National Institute of Neurological Disorders and Stroke Grant PO1 NS27950, and a National Defense Science and Engineering Graduate Fellowship awarded to the first author. We thank Eric Loken and Jane Gray for assistance in running subjects and data analysis. We also thank Marcia Johnson, Geoff Loftus, and an anonymous reviewer for comments on an earlier draft of this manuscript. Address correspondence to D. L. Schacter, Department of Psychology. Harvard University, 33 Kirkland St., Cambridge, MA 02138 (e-mail: norman@wjh.harvard.edu). word." For example, one list was composed of words associated with sweet, including sour, candy, sugar, bitter, good, and others. In Deese's original studies, subjects were asked to recall each list after it was presented. Deese found that subjects tended to intrude nonstudied "theme words" in their recall of studied items. Roediger and McDermott extended this finding to the domain of recognition memory. Subjects were given a recognition test composed of studied words, nonpresented "theme words" associated with studied lists (hereafter referred to as critical lures), and other nonstudied words. Roediger and McDermott found that, on average, subjects made false alarms to .76 of the critical lures; the hit rate for studied items was actually slightly lower (.72).

Furthermore, Roediger and McDermott (1995) assessed subjects' recollective experiences at test by asking them to make remember/know judgments (Tulving, 1985) whenever they indicated that an item had been presented at study. The subjects were instructed to indicate remember if they consciously recollected specific details regarding the presentation of the word at study (such as the words that came immediately before or after the item, or something distinctive about how the word was said), and to indicate know if the item seemed familiar but they did not have a specific recollection of having encountered it at study. Studies using the remember/know procedure have, in general, found that the majority of false alarms are assigned know rather than remember responses (e.g., Gardiner, 1988); that is, subjects make false alarms to lures because the lures seem familiar, not because they consciously recollect having encountered the lure at study. However, Roediger and McDermott (1995) found that .48 of responses to critical lures were remember responses. If we take this result at face value, subjects are, with unprecedented frequency, coming up with 
vivid and detailed, but illusory, recollections of hearing the critical lures at study.

The main purpose of this article is to elucidate the nature of this finding: When subjects make remember false alarms to nonstudied items, what are they remembering? It is possible that subjects are experiencing an extremely strong feeling of familiarity when they encounter critical lures, and that the overwhelming strength of this feeling of familiarity leads them to give a remember response even though they are not, in fact, remembering anything specific about encountering the word at study. Previous studies have demonstrated that remembering versus knowing need not simply reflect subjects' confidence in their memories: There can be low-confidence remember responses and high-confidence know responses (Rajaram, 1993). However, it is still possible that remember false alarms in the Roediger and McDermott (1995) paradigm are based on high-confidence feelings of familiarity (see Donaldson, 1996, for relevant discussion). Another possibility is that subjects actually are recollecting specific details from the study episode; if so, our task is to determine exactly what subjects are remembering when they falsely recognize critical lures.

Our first experiment was designed to induce more careful scrutiny of recollective experience triggered by critical lures. According to the source-monitoring framework developed by Johnson and colleagues (Johnson, Hashtroudi, \& Lindsay, 1993), two distinct factors contribute to false recognition: (1) the extent to which the qualitative characteristics of true and false memories are similar, and (2) the extent to which subjects take advantage of whatever differences might exist between true and false memories. Roediger and McDermott's (1995) finding of nearequivalent responding to studied items and critical lures on the recognition test suggests that subjects' memories of studied items and critical lures are, to them, indistinguishable. However, it is possible that differences exist and that, if pressed to adopt more stringent monitoring criteria (cf. Dodson \& Johnson, 1993; Lindsay \& Johnson, 1989), subjects will be able to resist claiming that they consciously recollect critical lures' being presented at study.

Towards this end, we replicated Roediger and McDermott's (1995) paradigm and, in addition, asked subjects to explain their responses on the recognition test. Thus, when subjects claimed to remember a particular word, we asked them to write down exactly what they remembered about the presentation of that item at study. If subjects are not recollecting specific details (i.e., if their "memories" of critical lures are composed of extremely strong, though nonspecific, feelings of familiarity), asking them to explain their remember responses will alert them to this state of affairs, and the subjects should change their responses to know or new. However, if subjects are indeed recollecting specific information when they make remember responses to critical lures, then the proportion of remember responses should remain largely unchanged when the subjects are asked to provide explanations; in this case, the subjects' explanations should provide a window into the qualitative characteristics of their false recognitions.
We also examined veridical and illusory recognition in a group of elderly adults. Older adults sometimes show increased susceptibility to memory distortions and illusions (cf. J. C. Bartlett, Strater, \& Fulton, 1991; Cohen \& Faulkner, 1989; Dywan \& Jacoby, 1990; Rankin \& Kausler, 1979; Tun, Wingfield, Blanchard, \& Rosen, 1996; Tun, Wingfield, \& Rosen, 1995). We examined whether elderly adults would exhibit increased levels of false recognition, even when they were asked to explain what they "remembered" about words they believed were on the study list. Finally, we sought to relate age differences in false recall and recognition to age differences in the content of subjects' memories. Hashtroudi, Johnson, and Chrosniak (1990) and Hashtroudi, Johnson, Vnek, and Ferguson (1994) argued that elderly subjects' poor source monitoring stemmed from impaired memory for qualities that discriminated between sources (e.g., perceptual and spatial detail), coupled with plentiful recall of elaborative information (e.g., thoughts and feelings), which tends to be less useful for source monitoring. These factors might also be responsible for elderly subjects' increased susceptibility to false recall and recognition.

\section{EXPERIMENT 1}

Our goal in Experiment 1 was to determine whether or not younger and older adults recollected specific information when they made remember false alarms to critical lures and, if so, to gain insight into the nature of the recollected information. To accomplish this goal, we had subjects write down brief explanations for their responses on the recognition test. We reasoned that explanations would make subjects more aware of the extent to which they were recollecting specific details; therefore, if subjects were, in fact, failing to recall details in conjunction with critical lures, we expected subjects in the explanation condition to notice this and to withhold their remember responses accordingly.

\section{Method}

Subjects. Twenty-four Harvard University undergraduates (approximate mean age $=19$ years) and 24 elderly adults (mean age $=$ 68.0 years, range $=62-79$ years) participated in the experiment, which took approximately $1.5 \mathrm{~h}$ to complete. The subjects were paid $\$ 15$ for their participation.

Materials. We used the 24 lists employed by Roediger and McDermott (1995). These lists were generated by choosing 24 "theme words" (one word for each list); for each theme word, the corresponding list was generated by using the Russell and Jenkins (1954) word-association norms to obtain the 15 words most associated with the critical word. Occasionally, Roediger and McDermott replaced one of the first 15 associates with another word which, in their opinion, seemed more likely to elicit the theme word. For example, the list corresponding to thief was steal, robber, crook, burglar, money, cop, bad, rob, jail, gun, villain, crime, bank, bandit, criminal.

The 24 lists were divided into three sets for counterbalancing purposes; each set served equally often in the three experimental conditions (see below). Subjects studied 16 lists, followed by a 96 -item recognition test. The test contained (1) 48 studied items (the 1 st, 8 th, and 10 th items, from each of the 16 studied lists), (2) the 16 critical lures - theme words corresponding to the 16 studied lists, (3) 24 new words (the 1st, 8 th, and 10th items, from each of the 8 nonstudied 
lists), and (4) 8 new theme words (theme words corresponding to the 8 nonstudied lists).

Design. The main design consisted of two between-group variables, age (young vs. elderly adults) and retrieval condition (explanation vs. no explanation required on the recognition test), and two within-group variables, study condition (study + recall vs. study + arithmetic) and item type (studied vs. critical lure). The studycondition manipulation was included to maximize the similarity between our paradigm and that of Roediger and McDermott (1995). Because this manipulation had no bearing on the primary questions being addressed and was not involved in any theoretically relevant main effects or interactions, study condition was omitted from all statistical analyses reported below.

In the study phase, two sets of 8 lists were presented. For one set of 8 lists, subjects performed arithmetic problems following each list (study + arithmetic condition). For the second set of 8 lists, subjects performed immediate free recall after each list (study + recall condition). The 16 lists were ordered randomly with respect to one another; an auditory signal (either two knocks or two beeps) that immediately followed the list informed the subjects of which postlist task to perform. Items from the remaining (nonpresented) set of 8 lists were used as lures on the recognition test.

Procedure. Subjects in the experiment were tested individually. All of them were informed that they would be hearing a series of lists of words presented on an audiotape; they were also told that after each list they would hear either two beeps or two knocks, which would indicate whether they should recall the list or solve arithmetic problems. Half of the subjects were told that if they heard two beeps, the experimenter would give them a sheet of paper on which they were supposed to write down the list they had just heard (last few items first, then the rest of the items in any order). The subjects were told to write down words only if they were "reasonably confident" that the word had appeared in the list; they were explicitly discouraged from guessing. These subjects were also informed that if they heard two knocks, the experimenter would give them a sheet containing arithmetic problems which they should work on as quickly as they could without sacrificing accuracy. The other half of our subjects were given the same instructions, except that beeps signaled arithmetic problems and knocks signaled recall. The subjects were given 2 min after each list to perform the postlist task.

Next, subjects cycled through 16 lists, performing arithmetic problems after 8 of the lists and performing immediate free recall after the other 8 lists. The experimenter presented each list by playing a prerecorded version of that list from an audiotape on which the words were presented at an approximate rate of one word per $1.5 \mathrm{sec}$. The subjects wore headphones connected to the audiotape player. Before each list, the number of that list ("list one," "list two," etc.) was spoken aloud on the tape. After this, the subjects were given a 5-min break, during which they conversed with the experimenter. After $5 \mathrm{~min}$ had elapsed, the subjects were given instructions for the recognition test. Half were assigned to the explanation condition, and half were assigned to the no-explanation condition.

Finally, the subjects were given a 96-item pen-and-paper recognition test. The subjects were asked to indicate for each item whether (1) they remembered encountering the word on one of the preceding eight lists (i.e., whether they consciously recollected some details pertaining to the presentation of that item on the audiotape), or (2) they knew that the word was presented on one of the preceding eight lists (i.e., the word seemed familiar but no specific details pertaining to the word's presentation came to mind), or (3) the word was not presented on one of the preceding eight lists. For each item, the subjects were instructed to first make an old/new judgment (by circling old or new on the test sheet); if they circled old, they were further instructed to circle either remember or know.

The subjects were given extensive instructions on how to make remember and know judgments, adapted from instructions used by Rajaram (1993). They were told that remembering "refers to the ability to become consciously aware again of some aspect or aspects of what happened or what was experienced at the time the word was presented" and were given examples of the kinds of information they might recall: what the word sounded like when it was presented on the audiotape, the word presented immediately before or after the word in question, something that happened in the room when the word was presented, what they were thinking and doing when they heard the word.

For know judgments, subjects were told that "Know responses should be made when you recognize that the word was in the study list but you cannot consciously recollect anything about its actual occurrence or what happened or what was experienced at the time of its occurrence. In other words, circle know when you are certain of recognizing the words, but these words fail to evoke any specific conscious recollection from the study episode." The subjects were explicitly reminded that they should make their remember/know judgment for a particular word with respect to its presentation on the audiotape, not whether or not they had written the word on the recall test.

In addition to the instructions above, subjects in the explanation condition were told to write following each item "why [they] wrote remember (old), know (old), or new, and how confident [they are] about whether the word is old or new." They were given examples of explanations for remember responses ("I remember how the word sounded on the tape--I'm sure it's old"), know responses ("It seems very familiar, but nothing specific comes to mind-I'm sure it's old"), and new responses ("It seems a little bit familiar, but I don't think I saw it-probably new"). The instructions emphasized that explanations for remember responses should include what exactly the subject remembered about encountering the word at study.

\section{Results and Discussion}

Free recall. All statistical comparisons (here and elsewhere in the paper) were planned and used an alpha level of .05 . Subjects' recall data are displayed in Table 1. Overall, subjects showed a robust false-recall effect, recalling $45 \%$ of critical lures as compared with $58 \%$ of studied items. From the age-difference scores in Table 1, we can conclude that young subjects recalled significantly more studied words than did elderly subjects $[t(46)=9.02]$ but that elderly subjects recalled more critical lures than did young subjects $[t(46)=1.99$; the latter effect was marginally significant]. From the item-type difference scores in Table 1, we can conclude that young subjects recalled significantly more studied items than critical lures $[t(23)=5.59]$. In contrast to younger adults, however, older adults actually recalled nonsignificantly more critical lures than studied items $[t(23)<1]$. An analysis of variance (ANOVA) revealed a highly significant age $\times$ item type interaction $\left[F(1,46)=21.56, M S_{\mathrm{e}}=.029\right]$.

We should note that, in addition to recalling more critical lures than did young subjects, elderly subjects also made significantly more noncritical-lure intrusions $(M=$

Table 1

Proportions of Items Recalled in Experiment 1, as a Function of Age and Item Type

\begin{tabular}{lccc}
\hline \multirow{2}{*}{\multicolumn{1}{c}{ Item Type }} & \multicolumn{2}{c}{ Age } & Age Difference \\
\cline { 2 - 4 } & Young & Elderly & \begin{tabular}{c} 
Score \\
\hline Studied
\end{tabular} \\
Critical lure & .67 & .48 & $.19(.04)$ \\
Item type difference score & .38 & .51 & $-.13(.13)$ \\
\hline
\end{tabular}

Note-Numbers in parentheses are $95 \%$ confidence intervals for difference scores. 
1.27 per list, $S E=.17)$ than did young subjects $[M=.70$ per list, $S E=.08 ; t(46)=2.97]$.

Recognition. Results from the recognition tests are given in Table 2, which contains data on old responses (obtained by summing remember and know responses), remember responses, and know responses.

From Table 2, we can conclude that our subjects showed a robust false-recognition effect. Overall, the false-alarm rate to critical lures was .78 , in contrast to a hit rate for studied items of .77. Also, we can see that a large proportion of subjects' hits to studied items and false alarms to critical lures were remember responses $(.69$ for studied items, .60 for critical lures). Since baseline false-alarm rates varied from condition to condition, we derived a set of corrected recognition scores by subtracting false alarms to new words from hits to studied items, and by subtracting false alarms to new theme words from false-alarms to critical lures. These corrected recognition scores, which are used in all statistical analyses that follow, were derived separately for old, remember, and know responses.

Data were analyzed using ANOVAs that included age, retrieval condition, and item type; separate ANOVAs were conducted for corrected old, remember, and know responses. To illustrate the effects of age on recognition performance, we derived age (young - elderly) difference scores for corrected old, remember, and know responses to studied items and critical lures; these difference scores are depicted in Figure 1.

From Figure 1, it is evident that young subjects made significantly more old responses to studied items than did elderly subjects $[t(46)=3.94]$, whereas age had no effect on old responses to critical lures. The age $\times$ item type interaction for old responses approached significance $\left[F(1,44)=3.12, M S_{\mathrm{e}}=.028\right]$. For remember responses, the age $\times$ item type interaction was significant $[F(1,44)=$ 9.903, $\left.M S_{\mathrm{e}}=.016\right]$ : Elderly subjects made nonsignifi-

Table 2

Proportions of Items Given Old, Remember, and Know Responses on the Recognition Test in Experiment 1 (With Standard Errors), as a Function of Age, Retrieval Condition, and Item Type

\begin{tabular}{|c|c|c|c|c|c|c|c|c|}
\hline \multirow[b]{2}{*}{ Item Type } & \multicolumn{4}{|c|}{ No Explanation } & \multicolumn{4}{|c|}{ Explanation } \\
\hline & Young & $S E$ & Elderly & $S E$ & Young & $S E$ & Elderly & $S E$ \\
\hline \multicolumn{9}{|c|}{ Old Responses } \\
\hline Studied & .79 & .03 & .73 & .04 & .79 & .03 & .76 & .04 \\
\hline New & .08 & .02 & .15 & .03 & & .02 & & .05 \\
\hline Critical lure & .65 & .08 & .80 & .06 & .77 & .04 & .90 & .03 \\
\hline & .13 & .04 & .21 & .04 & .10 & .03 & .31 & .07 \\
\hline \multicolumn{9}{|c|}{ Remember Responses } \\
\hline & .53 & .04 & .51 & .05 & .54 & .05 & .55 & .08 \\
\hline & .01 & .01 & .05 & .0 & .01 & .01 & .10 & .04 \\
\hline col lure & .39 & .06 & .58 & .08 & .32 & .05 & .59 & .10 \\
\hline New theme & .00 & .00 & .10 & .04 & .00 & .00 & .16 & .07 \\
\hline \multicolumn{9}{|c|}{ Know Responses } \\
\hline Studied & .26 & .05 & .22 & .05 & .25 & .04 & .21 & .06 \\
\hline New & .07 & .02 & .10 & .04 & .06 & .02 & .06 & .02 \\
\hline Critical lure & .26 & .07 & .22 & .06 & .45 & .05 & .31 & .10 \\
\hline New theme & .13 & .04 & .10 & .03 & .10 & .03 & .16 & .04 \\
\hline
\end{tabular}

cantly more remember responses to critical lures than did young subjects $[t(46)=1.567]$, whereas young subjects made nonsignificantly more remember responses to studied items than did elderly subjects $[t(46)=1.288]$. Notably, this age $\times$ item type interaction for remember responses was observed in both the explanation and the no-explanation conditions; that is, there was no age $\times$ item type $\times$ retrieval condition interaction $[F(1,44)=$ $\left..174, M S_{\mathrm{e}}=.016\right]$.

Next, to illustrate the effects of retrieval condition on recognition performance, we derived retrieval-condition (explanation - no explanation) difference scores for corrected old, remember, and know responses to studied items and critical lures; these difference scores are depicted in Figure 2. As is evident from the figure, there were no significant main effects of retrieval condition on recognition. For know responses, the item type $\times$ retrieval condition interaction was significant $[F(1,44)=$ $\left.5.41, M S_{\mathrm{e}}=.030\right]$. For critical lures, subjects made nonsignificantly more know responses in the explanation condition than in the no-explanation condition, but there was no corresponding effect of retrieval condition for studied items.

Only one effect involved both age and retrieval condition: a significant item type $\times$ retrieval condition $\times$ age interaction for corrected know responses $[F(1,44)=4.13$, $\left.M S_{\mathrm{e}}=.030\right]$. This three-way interaction stems from the fact that explanation increased know responses to critical lures in young subjects but not in elderly subjects, and explanation did not increase know responses to studied items in either age group.

Content of Explanations: Qualitative Observations. The preceding analyses established that both younger and older adults made remember false alarms to critical lures in the explanation condition. We examined the explanations that subjects provided in conjunction with these remember false alarms to critical lures in order to obtain preliminary information concerning two questions: First, were there any attributes that might allow us to distinguish veridical recognition (remember hits) from false recognition (remember false alarms to critical lures)? Second, what kinds of information are false recognitions based on?

We found that the majority of explanations (given in response to both studied items and critical lures) did not refer to memory for presentation of the item per se; rather, most explanations simply referred to remembered information that was semantically related to the target item. The most common kinds of explanations were memory for related words (e.g., "needle: This word came in the same list as thread") and memory for thoughts or associations related to the target word (e.g., "music: I thought about music I heard this morning"; "thief: heard word 'stop,' thought of screaming 'stop thief '").

Explanations given to critical lures belonged almost entirely to the above two categories. However, explanations given to studied words sometimes referred more directly to the circumstances surrounding the word's presentation at study. For example, subjects occasionally 


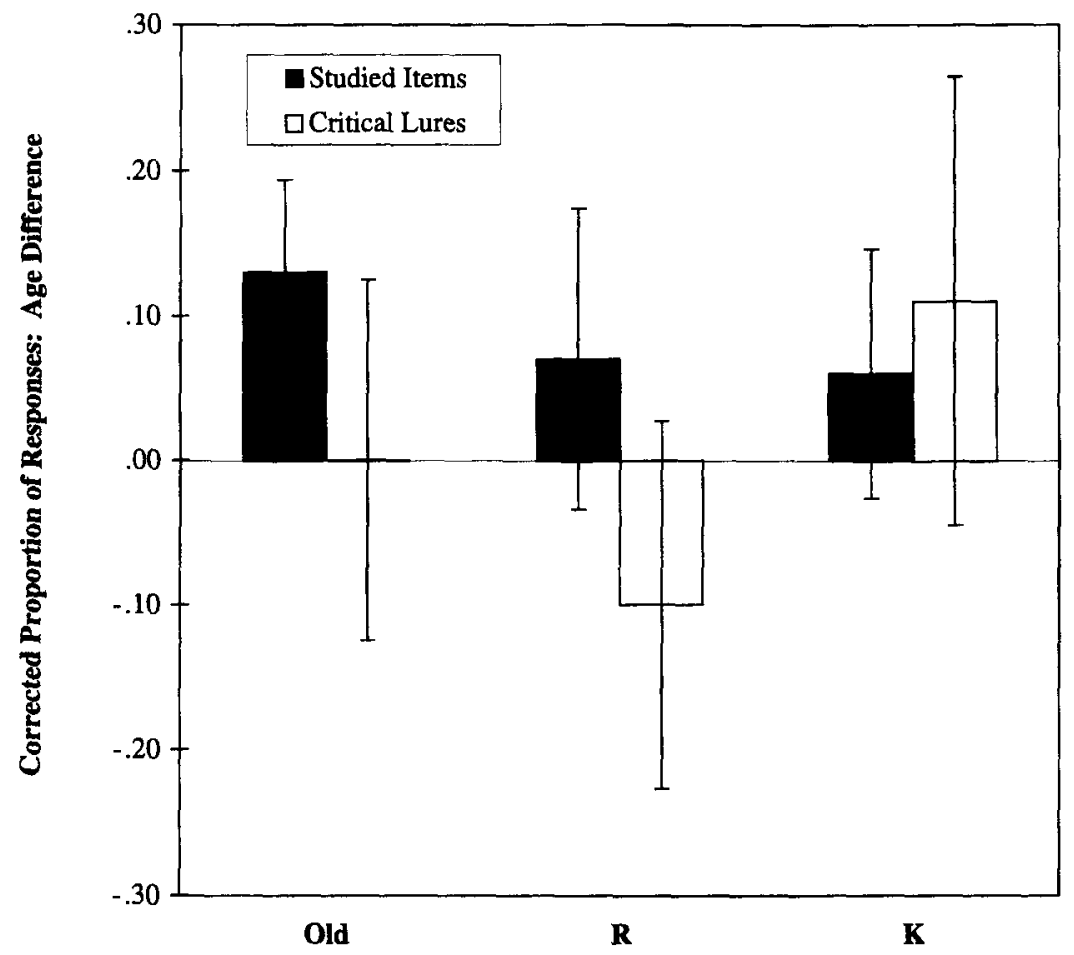

Figure 1. Age (young - elderly) difference scores for corrected old, remember (R), and know (K) responses from the Experiment 1 recognition test, as a function of item type. Error bars indicate $95 \%$ confidence intervals.

cited reactions triggered by the target word when it was presented (e.g., "nice: I remember thinking what a bland word"; "slumber: This word stood out"), the target word's list context (e.g., "nurse: I remember hearing this word toward the end of the physician list"; "woman: This came after 'dress" "), and sensory characteristics of the target word (e.g., "candy: I remember the sound of this word").

In summary, Experiment 1 yielded two main results. First, we found that subjects continued to make remember false alarms to critical lures even when they were required to focus on the details of their recollections. Second, relative to their recall and recognition of previously heard words, older adults exhibited enhanced susceptibility to false recall and recognition (cf. Tun et al., 1996; Tun et al., 1995, who recently reported similar findings for recall and recognition, respectively).

The fact that remember false alarms to critical lures occurred frequently in the explanation condition allowed us to obtain preliminary information about what subjects remembered when they falsely recognized critical lures. From subjects' explanations, it appears that both younger and older adults were primarily retrieving associative information in conjunction with both critical lures and studied items. Explanations referring to sensory and contextual details were quite rare overall, although they occurred more frequently in response to studied items than in response to critical lures. The bulk of subjects' explanations dealt with such attributes as list membership and memory for thoughts related to the target word.
However, these observations must be viewed as merely suggestive. Explanation data are not well suited to making precise, quantitative claims about the contents of subjects' memories; importantly, we were unable to detect any differences between explanations generated by young and elderly subjects. In Experiment 2, we attempted to provide a more rigorous assessment of the qualitative characteristics of veridical and illusory memories.

\section{EXPERIMENT 2}

To clarify our preliminary observations, we adopted a variant of a procedure introduced by Johnson, Foley, Suengas, and Raye (1988). In their study, people rated various characteristics of memories for real and imagined events on a 7-point scale. Actual events were given higher ratings than imagined events on sensory characteristics (visual detail, sound, smell, taste) and characteristics having to do with spatiotemporal context (location, setting, spatial arrangement of objects and people, and temporal characteristics). Imagined events, by contrast, were rated as being more intense and thought about more often than actual events.

To provide quantitative information about the characteristics of recollections associated with studied words and critical lures, respectively, we used a procedure similar to Johnson et al.'s (1988) in which we asked subjects questions about different facets of their memories. Four of the questions were meant to assess the extent to which 


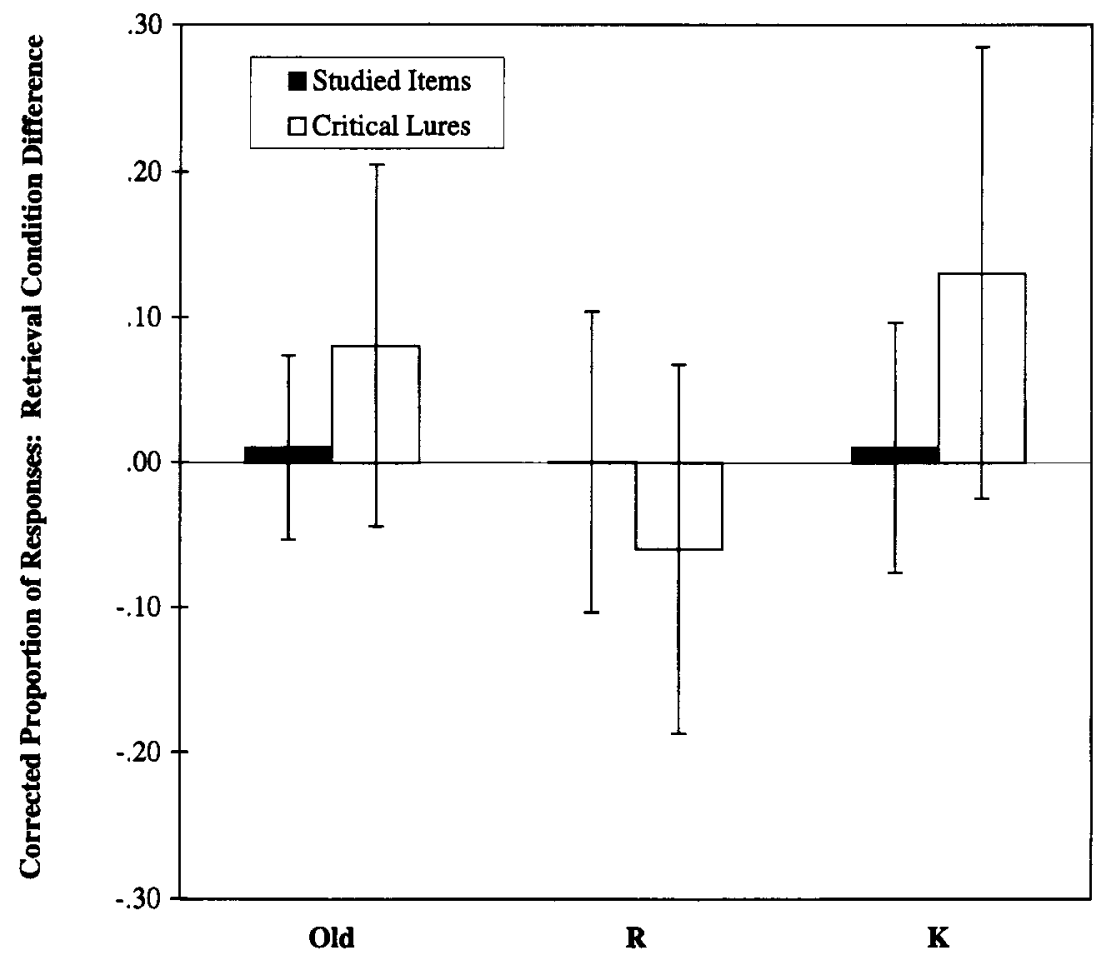

Figure 2. Retrieval condition (explanation - no explanation) difference scores for corrected old, remember (R), and know (K) responses from the Experiment 1 recognition test, as a function of item type. Error bars indicate $95 \%$ confidence intervals.

subjects recollected the specific circumstances of a word's presentation. Specifically, these four questions regarded (1) Memory for sound - Do you remember what the word sounded like when it was presented at study? (2) Memory for list position-Do you remember where in the list the word was presented? (3) Memory for neighboring words-Do you remember the words that came immediately before or after this word? (4) Memory for reaction Do you remember reacting to this word in some way at the moment it was presented?

Two other questions were devised in an attempt to probe the extent to which subjects remembered associative information in conjunction with the target word. These two questions regarded: (1) Memory for thoughts -Do you remember having a specific thought relating to this word at study? (2) Memory for associations - Do you remember associating this word with other presented words?

Based on our preliminary analysis of the content of subjects' explanations from Experiment 1, we made two main predictions: (1) Both accurate and illusory memories would contain more associative information than sensory and contextual detail, and (2) illusory memories would contain less sensory and contextual detail than true memories.

In view of older adults' enhanced susceptibility to false recognition in Experiment 1, we again tested a group of elderly adults in Experiment 2, in an attempt to determine whether any differences in the content of subjects' memories could account for the observed age difference. Although the qualitative information gathered in Experiment 1 was too ambiguous to allow us to address this question, we expected that the rating procedure used in Experiment 2 would provide a more refined method for probing potentially subtle age-related differences in recollective experience.

\section{Method}

Subjects. Twenty-four Harvard University undergraduates (approximate mean age $=19$ years) and 24 elderly subjects (mean age $=$ 67.0 years, range $=61-72$ years) participated in the experiment which took approximately $1.5 \mathrm{~h}$ to complete. The subjects were paid $\$ 15$ for their participation.

Materials. The materials used (both the word lists and the recognition tests) were identical to those employed in Experiment 1. However, instead of using an audiotape player to present stimuli, study list words were presented (over headphones) using an Apple Macintosh Quadra 950 computer. Also, unlike in the previous experiment, the recognition test was presented on a computer.

Design and Procedure. The study phase and the test list of this experiment were identical to those of Experiment 1. Also as in Experiment 1 , study condition (study + recall vs. study + arithmetic) was not involved in any theoretically significant main effects or interactions, and hence was omitted from all statistical analyses presented in the Results and Discussion section below.

After subjects completed the study phase, they were given instructions for the recognition test. They were told that a series of words would appear on the computer screen. They were instructed to rate, for each word, how confident they were that the word had been (or had not been) presented at study: Specifically, they were 
told to press " 1 " if they were sure the word was new, to press " 2 " if they thought the word was probably new but they weren't sure, to press " 3 " if they thought the word was probably old but they weren't sure, and to press " 4 " if they were sure that the word was old.

Furthermore, the subjects were told that if they pressed " 3 " or "4" (thereby indicating that they thought the word was old), they would be asked to respond to the six questions described above in the introduction to Experiment 2 (memory for sound, list position, neighbor, reaction, association, and thought). For each question, the subjects were instructed to respond by using the numbers 1 to 7 , with a response of 1 indicating no memory and a response of 7 indicating a vivid memory. They were encouraged to take their time and to think carefully about each of the questions they answered. For a given item, the six questions were presented in a random order.

\section{Results and Discussion}

Recall. Table 3 contains the recall data from Experiment 2. As in Experiment 1, subjects showed a robust false-recall effect overall: for studied lists followed by recall tests, they recalled $41 \%$ of critical lures, as compared with $61 \%$ of studied items. From the age difference scores in Table 3, we can conclude that young subjects recalled significantly more studied words than did elderly subjects $[t(46)=5.94]$ but that elderly subjects recalled significantly more critical lures than did young subjects $[t(46)=2.08]$. From the item type difference scores in Table 3 , we can conclude that young subjects recalled significantly more studied items than critical lures $[t(23)=$ $6.21]$. Older adults, however, recalled nonsignificantly more critical lures than studied items $[t(23)=1.45]$. An ANOVA revealed a highly significant age $\times$ item type interaction $\left[F(1,46)=15.68, M S_{\mathrm{e}}=.03\right]$.

In this experiment, the number of noncritical-lure intrusions did not differ significantly for elderly subjects $(M=.80$ noncritical-lure intrusions per list, $S E=.09)$ and young subjects $(M=.90$ per list, $S E=.21 ; t<.5)$.

Recognition. Recognition data are presented in Table 4. Overall, subjects gave either a 3 (probably old) or a 4 (sure it's old) response to .59 of critical lures, compared with .71 of studied items. Table 5 examines the effects of age and item type on old responses (i.e., the proportion of trials in which subjects gave either a 3 or a 4 response), which have been corrected for baseline false alarms in the manner described in Experiment 1. From the agedifference scores in Table 5, we can conclude that young subjects made significantly more old responses to studied items than did elderly subjects $[t(46)=2.79]$. For critical lures, however, elderly subjects made nonsignificantly more old responses than did young subjects

Table 3

Proportions of Items Recalled in Experiment 2, as a Function of Age and Item Type

\begin{tabular}{lccc}
\hline \multirow{2}{*}{ Item Type } & \multicolumn{2}{c}{ Age } & Age Difference \\
\cline { 2 - 3 } \multicolumn{1}{c}{ Soung } & Elderly & Score \\
\hline Studied & .69 & .54 & $.15(.05)$ \\
Critical lure & .34 & .47 & $-.13(.13)$ \\
Item type difference score & $.35(.12)$ & $.07(.09)$ & \\
\hline
\end{tabular}

Note-Numbers in parentheses are $95 \%$ confidence intervals for difference scores. $[t(46)=1.91]$. From the item-type difference scores in Table 5, we can conclude that young subjects made significantly more old responses to studied items than to critical lures $[t(46)=5.27]$, whereas elderly subjects made only slightly more old responses to studied items than to critical lures $[t(46)<1]$. Finally, we found a strong age $\times$ item type interaction for corrected old responses $\left[F(1,46)=12.64, M S_{\mathrm{e}}=.024\right]$.

Attributes of veridical and illusory memories. For all of the qualitative analyses, we will focus on ratings given in conjunction with 4 (sure the word is old) responses. Table 6 contains these attribute ratings. One young subject was omitted from all analyses of qualitative data because this subject did not make any false alarms to critical lures.

On the basis of our preliminary examination of subjects' explanations in Experiment 1, we had predicted that their memories would contain more associative information than sensory and contextual detail. Consistent with this prediction, we found that, for both studied items and critical lures, both young and elderly subjects gave higher ratings on the association dimension than on the oth five dimensions. This observation was confirmed by $t$ tests $(t>4$ for each of the pairwise comparisons between as sociation and the other five dimensions, for both studied items and critical lures).

Our primary interest in the qualitative ratings was ascertaining which dimensions discriminated between studied items and critical lures. Toward this end, we conducted $t$ tests on difference scores obtained by subtracting ratings given to critical lures from ratings given to studied items. Figure 3 depicts these difference scores; $t$ tests were carried out separately for young and elderly subjects for each of the six dimensions. For young subjects, the difference scores for sound, list position, reaction, and thought all significantly differed from zero [for sound, $t(22)=$ 4.27 ; for list position, $t(22)=3.99$; for reaction, $t(22)=$ 3.14 ; for thought, $t(22)=2.88$ ]. The difference scores for neighbor and association did not approach significance [for neighbor, $t(22)=1.35$; for association, $t(22)=1.31$ ]. For elderly subjects, difference scores for sound, list position, and thought were significantly different from zero [for sound, $t(23)=3.24$; for list position, $t(23)=2.43$; for thought, $t(23)=3.21]$. Of the other three dimensions, the difference score for reaction approached significance $[t(23)=1.89]$, but the difference scores for neighbor and association did not (both $t \mathrm{~s}<1$ ).

We also conducted $t$ tests to determine whether there were any age differences in the magnitude of these difference scores. We found that, while list position discriminated between true and false memories for both age groups, the difference between true and false memories was significantly larger for young subjects $[t(45)=2.08]$. Likewise, the difference between true and false memories on the sound dimension was larger for young subjects than for elderly subjects; this difference approached significance $[t(45)=1.85]$. These last two results indicate that the difference in sensory and contextual detail be- 
Table 4

Proportions of Items Assigned Each Confidence Rating in Experiment 2 (With Standard Errors), as a Function of Age and Item Type

\begin{tabular}{|c|c|c|c|c|c|c|c|c|c|c|c|c|c|c|c|c|}
\hline \multirow[b]{4}{*}{ Item Type } & \multicolumn{16}{|c|}{ Confidence Rating } \\
\hline & \multicolumn{4}{|c|}{1} & \multicolumn{4}{|c|}{2} & \multicolumn{4}{|c|}{3} & \multicolumn{4}{|c|}{4} \\
\hline & \multicolumn{2}{|c|}{ Young } & \multicolumn{2}{|c|}{ Elderly } & \multicolumn{2}{|c|}{ Young } & \multicolumn{2}{|c|}{ Elderly } & \multicolumn{2}{|c|}{ Young } & \multicolumn{2}{|c|}{ Elderly } & \multicolumn{2}{|c|}{ Young } & \multicolumn{2}{|c|}{ Elderly } \\
\hline & Prop. & $S E$ & Prop. & $S E$ & Prop. & $S E$ & Prop. & $\overline{S E}$ & Prop. & $S E$ & Prop. & $S E$ & Prop. & $\overline{S E}$ & Prop. & $S E$ \\
\hline Studied & .10 & .02 & .18 & .03 & .16 & .02 & .15 & .02 & .14 & .01 & .14 & .02 & .60 & .03 & .53 & .04 \\
\hline New & .55 & .06 & .65 & .06 & .41 & .06 & .27 & .05 & .03 & .01 & .05 & .02 & .01 & .01 & .03 & .01 \\
\hline Critical lure & .21 & .03 & .16 & .03 & .29 & .03 & .18 & .04 & .22 & .03 & .18 & .02 & .30 & .04 & .49 & .06 \\
\hline New theme & .51 & .06 & .63 & .05 & .42 & .06 & .26 & .04 & .06 & .02 & .08 & .02 & .02 & .01 & .04 & .02 \\
\hline
\end{tabular}

tween true and false memories was less pronounced in elderly subjects than in young subjects.

We had predicted that memories of studied items would contain more sensory and contextual detail than memories of critical lures. Our finding that sound, list position, and reaction (all "sensory and contextual" dimensions) discriminated between studied items and critical lures and that association failed to discriminate significantly between studied items and critical lures is consistent with this prediction. Neighbor failed to significantly discriminate between studied items and critical lures, probably because subjects failed to distinguish between "memory for words immediately preceding and following the target word" (a contextual attribute) and "memory for words belonging to the same list as the target word" (an associative attribute). Lastly, we found that thought (a nominally "associative" attribute) discriminated between veridical and illusory memories, indicating that studied items triggered a greater number of specific remembered thoughts related to the item than did critical lures.

On the whole, our results coincide well with other findings in the source-monitoring literature. In particular, Mather, Henkel, and Johnson (in press) used a paradigm similar to ours and, like us, found that false memories for critical lures were characterized by less auditory detail and fewer remembered feelings and reactions than memories for presented words. Many of the differences we found between illusory and veridical memories also hold true for comparisons of perceived versus imagined items (e.g., Johnson, Raye, Foley, \& Kim, 1982, found that subjects remembered more position information in conjunction with perceived events than with imagined events). Lastly, Schooler, Gerhard, and Loftus (1986) found that when subjects claimed to remember a nonexistent object (whose existence was suggested by means of a misleading postevent question), their descriptions contained less

Table 5

Corrected Proportions of Items Given Old Responses on the Recognition Test in Experiment 2, as a Function of Age and Item Type

\begin{tabular}{lccc}
\hline \multirow{2}{1}{ Item Type } & \multicolumn{2}{c}{ Age } & \multirow{2}{*}{ Age Difference } \\
\cline { 2 - 3 } & Young & Elderly & Score \\
\hline Studied & .70 & .59 & $.11(.08)$ \\
Critical lure & .44 & .55 & $-.11(.12)$ \\
Item type difference score & $.26(.10)$ & $.04(.08)$ & \\
\hline
\end{tabular}

Note-Numbers in parentheses are $95 \%$ confidence intervals for difference scores. sensory detail and more references to cognitive processes than descriptions of objects that were actually presented. On the one hand, it is encouraging to find broad-based commonalities between memory illusions (e.g., diminished sensory vividness for false memories). On the other hand, extensive differences exist between our paradigm and that of Schooler et al., and it would be a mistake to expect all memory illusions to have identical characteristics.

\section{GENERAL DISCUSSION}

Our results provide new insights into illusory recognition of semantic associates of previously presented words. Experiment 1 provides evidence against the claim that false recognition of critical lures is driven by strong (but nonspecific) feelings of familiarity: In the explanation condition, young and elderly adults cited specific details from the study phase to support their remember false alarms to critical lures. Based on preliminary analysis of these explanations and analysis of ratings given to highconfidence recognition responses in Experiment 2, we conclude that veridical recognition of previously studied words and illusory recognition of critical lures are both based in large part on associative information: memory for words and thoughts associated in some way with the target word. We should note, however, that subjects in Experiment 2 still claimed to remember a considerable amount of sensory and contextual information in conjunction with studied items and, more strikingly, in conjunction with critical lures. One possible explanation for the latter finding is that subjects were mistakenly attributing sensory and contextual details associated with studied items to critical lures (for evidence in favor of this claim, see Mather et al., in press).

Importantly, Experiment 2 revealed that subjects remembered more sensory and contextual details in conjunction with veridical recognition of previously heard words than in conjunction with false recognition of critical lures, including information concerning the sound and list position of the word and reactions triggered by the words at encoding. This finding meshes well with data from a recent PET study conducted by Schacter, Reiman, et al. (1996), which examined changes in regional cerebral blood flow during veridical recognition of previously heard words and illusory recognition of critical lures. In the PET study, veridical recognition was distinguished from illusory recognition by activation in tem- 
Table 6

Qualitative Ratings Given in Conjunction with "4" Responses in Experiment 2 (With Standard Errors), as a Function of Age and Item Type

\begin{tabular}{|c|c|c|c|c|c|c|c|c|c|c|c|c|c|}
\hline \multirow[b]{2}{*}{ Item Type } & \multirow[b]{2}{*}{ Age } & \multicolumn{2}{|c|}{ Sound } & \multicolumn{2}{|c|}{ List Position } & \multicolumn{2}{|c|}{ Neighbor } & \multicolumn{2}{|c|}{ Reaction } & \multicolumn{2}{|c|}{ Association } & \multicolumn{2}{|c|}{ Thought } \\
\hline & & Rating & $S E$ & Rating & $S E$ & Rating & $S E$ & Rating & $S E$ & Rating & $S E$ & Rating & $S E$ \\
\hline \multirow[t]{2}{*}{ Studied } & young & 4.25 & .30 & 5.02 & .21 & 4.45 & .23 & 5.18 & .28 & 6.47 & .10 & 5.32 & .24 \\
\hline & elderly & 4.5 & .41 & 4.80 & .28 & 3.61 & .32 & 4.94 & .32 & 6.21 & .12 & 5.19 & .29 \\
\hline \multirow[t]{2}{*}{ Critical lure } & young & 3.35 & .33 & 4.14 & .33 & 4.11 & .34 & 4.61 & .33 & 6.22 & .26 & 4.72 & .35 \\
\hline & elderly & 4.14 & .37 & 4.46 & .27 & 3.58 & .35 & 4.59 & .33 & 6.12 & .15 & 4.79 & .28 \\
\hline
\end{tabular}

Note - One young subject was omitted from the analysis of qualitative data (see text for details).

poroparietal brain regions that have been implicated in auditory/phonological rehearsal processes (see Paulesu, Frith, \& Frackowiack, 1993).

This PET study also revealed that the same medial temporal structures were activated by both studied items and critical lures. This medial temporal activation may reflect the conscious recollection of associative information which is common to veridical and illusory memories (for evidence linking the medial temporal lobes to successful conscious recollection, see Schacter, Alpert, Savage, Rauch, \& Albert, 1996; see also Nyberg, McIntosh, Houle, Nilsson, \& Tulving, 1996; Schacter, Reiman, et al., 1995; Squire et al., 1992). Converging evidence for this claim comes from the recent finding that amnesic patients with medial temporal lobe damage exhibit less false recognition of critical lures than do controls (Schacter, Verfaellie, \& Pradere, 1996).

Our data also show clearly that older adults show more false recognition (relative to recognition of studied words) than do younger adults, even under conditions of increased scrutiny (i.e., explanation), thereby replicating and extending the work of Rankin and Kausler (1979) and Tun et al. (1996) on false recognition, as well as work on other memory illusions (Bartlett et al., 1991; Cohen \& Faulkner, 1989; Dywan \& Jacoby, 1990) in the elderly. Additional insight into elderly subjects' false recognition comes from our finding that sound and list position discriminate less well between true and false memories in elderly subjects than in young subjects. Our results are consistent with a number of other studies (e.g., Hashtroudi et al., 1990) which have argued that elderly subjects' poor memory for perceptual and contextual detail increases their vulnerability to source misattributions.

Thus far, we have discussed elderly subjects' increased susceptibility to false recognition in terms of the qualitative characteristics of true and false memories being more similar for elderly subjects than for young subjects. However, we should not neglect the possibility that poor monitoring (i.e., failure to properly take advantage of whatever qualitative differences might exist between veridical and illusory memories) also contributes to elderly subjects' false recognition. Elderly subjects show extensive memory monitoring and search deficits which resemble those found in frontal lesion patients (for a review, see Moscovitch \& Winocur, 1995; see also Shimamura, 1995, and Stuss, Eskes, \& Foster, 1994, for reviews

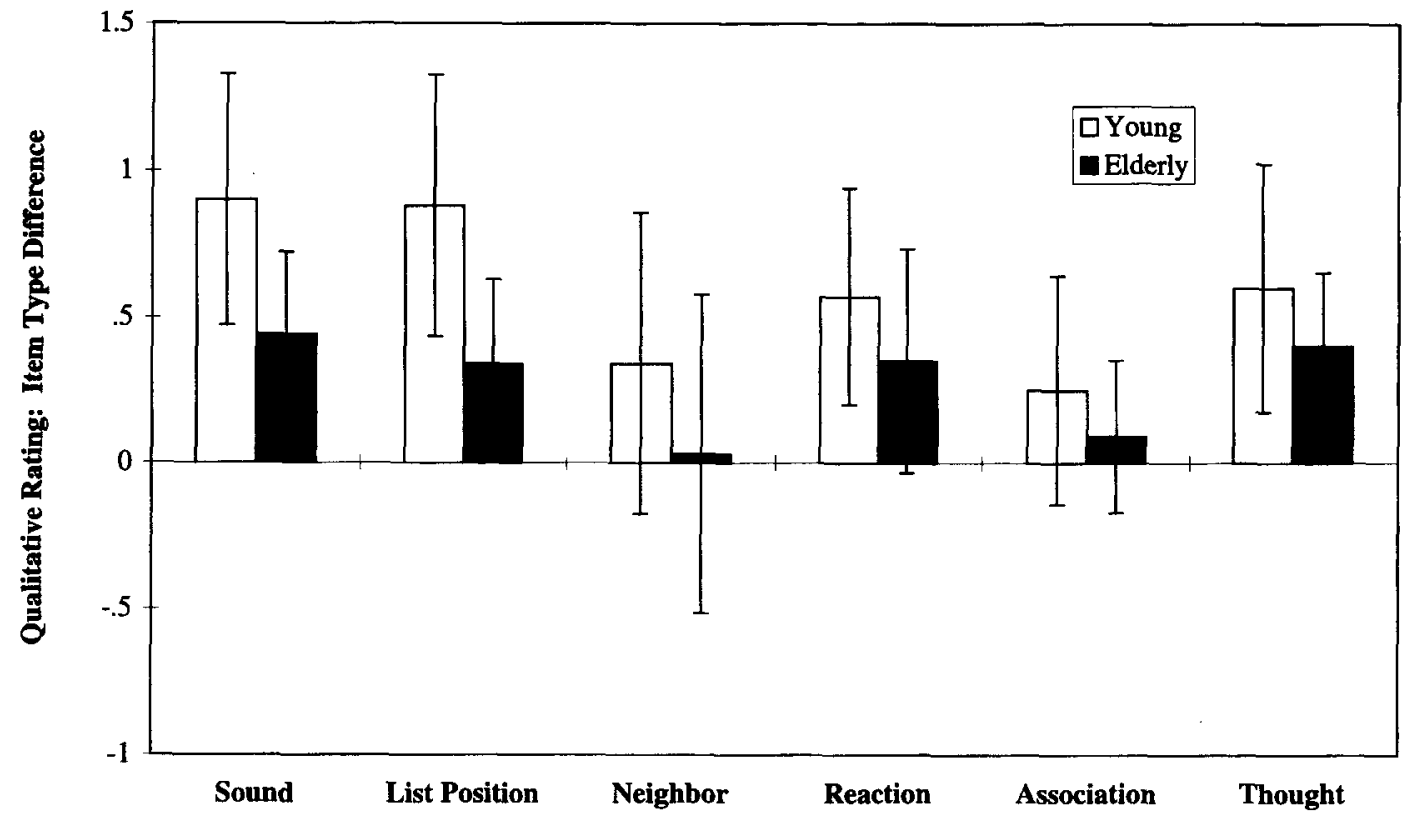

Figure 3. Item type (studied - critical lure) difference scores for qualitative ratings from Experiment 2 as a function of age. Error bars indicate $95 \%$ confidence intervals. 
of the effects of frontal lesions on memory). Based on this evidence, elderly subjects' monitoring difficulties have been attributed to age-related decay of prefrontal cortical structures. Additional evidence linking prefrontal structures to monitoring processes comes from neuroimaging studies which have found differential prefrontal activity in conjunction with effortful search and retrieval in episodic memory tasks (Kapur et al., 1995; Nyberg, Cabeza, \& Tulving, 1996; Schacter, Savage, Alpert, Rauch, \& Albert, 1996); appropriately, elderly subjects show abnormal patterns of prefrontal activity at retrieval during a stem-cued recall task (Schacter, Savage, et al., 1996).

The role of prefrontal-based monitoring processes in the Deese paradigm is highlighted by Schacter, Reiman, et al.'s (1996) finding that, at test, presentation of critical lures was associated with heightened activity in regions of prefrontal cortex (relative to presentation of studied words); Schacter, Reiman, et al. suggested that heightened frontal-lobe activity during presentation of critical lures reflects an attempt to scrutinize recollective experience associated with the critical lure. These observations raise the possibility that impaired frontal-lobe functioning in elderly subjects would make it more difficult for them to "resist" or oppose (Jacoby, 1991) illusory memories of critical lures. The ideas being discussed here are consistent with other recent findings which indicate that frontal-lobe damage can be associated with high levels of false recognition (Schacter, Curran, Galluccio, Milberg, \& Bates, 1996) and confabulation (Moscovitch, 1995).

In conclusion, we believe that an approach that combines the results of behavioral studies like this one, neuropsychological analyses, and neuroimaging studies will be most productive in enriching our understanding of memory illusions and distortions in both younger and older adults, thereby allowing us to achieve new insights into the constructive nature of human memory.

\section{REFERENCES}

Bartlett, F. C. (1932). Remembering. Cambridge: Cambridge University Press.

Bartlett, J. C., Strater, L., \& Fulton, A. (1991). False recency and false fame of faces in young adulthood and old age. Memory \& Cognition, 19, 177-188.

Bransford, J. D., \& Franks, J. J. (1971). The abstraction of linguistic ideas. Cognitive Psychology, 2, 331-350.

CoHEN, G. \& Faulkner, D. (1989). Age differences in source forgetting: Effects on reality monitoring and eyewitness testimony. $P s y$ chologv \& Aging, 4, 10-17.

DEESE, J. (1959). On the prediction of occurrence of particular verbal intrusions in immediate recall. Journal of Experimental Psychology, 58, $17-22$

DoDson, C. S., \& JoHnSon, M. K. (1993). Rate of false source attributions depends on how questions are asked. American Journal of Psi'chologi, 106. 541-557.

DOnaldson, W. (1996). The role of decision processes in remembering and knowing. Memory \& Cognition, 24, 523-533.

DYWAN, J., \& JACOBY, L. L. (1990). Effects of aging on source monitoring: Differences in susceptibility to false fame. Psychology \& Aging, 5, 379-387.

GARDINER, J. M. (1988). Functional aspects of recollective experience. Memony \& Cognition, 16, 309-313.
Garry, M., Manning, C., Loftus, E. F., \& Sherman, S. J. (1996). Imagination inflation: Imagining a childhood event inflates confidence that it occurred. Psychonomic Bulletin \& Review, 3. 208-214.

Hashtroudr, S., Johnson, M. K., \& Chrosniak, L. D. (1990). Aging and qualitative characteristics of memories for perceived and imagined complex events. Psychology \& Aging, 5, 119-126.

Hashtroudi, S., Johnson, M. K., Vnek, N., \& Ferguson, S. A. (1994). Aging and the effects of affective and factual focus on source monitoring and recall. Psychology \& Aging, 9, 160-170.

Hyman, I. E., Husband, T. H., \& Billings, F. J. (1995). False memories of childhood experiences. Applied Cognitive Psychology, 9, 181-197.

$J_{A C O B Y}$ L. L. (1991). A process dissociation framework: Separating automatic from intentional uses of memory. Journal of Memory \& Language, 30, 513-541.

Johnson, M. K., Foley, M. A., Suengas, A. G., \& Raye, C. L. (1988). Phenomenal characteristics of memories for perceived and imagined autobiographical events. Journal of Experimental Psychology: General, 117, 371-376.

Johnson, M. K., Hashtroudi, S., \& LindSay, D. S. (1993). Source monitoring. Psychological Bulletin, 114, 3-28.

Johnson, M. K., Raye, C. L., Foley, M. A., \& Kim, J. K. (1982). Pictures and images: Spatial and temporal information compared. Bulletin of the Psychonomic Society, 19, 23-26.

Johnson, M. K., RAYE, C. L., WANG, A. Y., \& TAYLoR, T. H. (1979). Fact and fantasy: The roles of accuracy and variability in confusing imaginations with perceptual experiences. Journal of Experimental Psychology: Human Learning \& Memory, 5, 229-240.

Kapur, S., Craik, F. I. M., Jones, C., Brown, G. H., Houle, S., \& TulviNG, E. (1995). Functional roles of prefrontal cortex in retrieval of memories: A PET study. NeuroReport, 6, 1880-1884.

LindSAY, D. S., \& JoHnson, M. K. (1989). Eyewitness suggestibility and memory for source. Memory \& Cognition, 17, 349-358.

Loftus, E. F., Miller, D. G., \& Burns, H. J. (1978). Semantic inte gration of verbal information into a visual memory. Journal of Ex perimental Psychology: Human Learning \& Memory, 4, 19-31.

Loftus, E. F., \& PickRell, J. E. (1995). The formation of false memories. Psychiatric Annals, 25. 720-725.

Mather, M., Henkel, L. A., \& Johnson, M. K. (in press). Evaluating characteristics of false memories: Remember/know judgments and memory characteristics questionnaire compared. Memory \& Cognition.

Moscovitch, M. (1995). Confabulation. In D. L. Schacter, J. T. Coyle G. D. Fischbach, M.-M. Mesulam, \& L. E. Sullivan (Eds.), Memory distortion: How minds, brains, and societies reconstruct the past (pp. 226-291). Cambridge, MA: Harvard University Press.

Moscovitch, M., \& Winocur, G. (1995). Frontal lobes, memory, and aging. In J. Grafman, K. J. Holyoak, \& F. Boller (Eds.), Structure and functions of the human prefrontal cortex (Annals of the New York Academy of Sciences, Vol. 769, pp. 119-150). New York: New Academy of Sciences.

Nyberg, L., Cabeza, R., \& Tulving, E. (1996). PET studies of encoding and retrieval: The HERA model. Psychonomic Bulletin \& Review, 3, 135-148.

Nyberg, L., McIntosh, A. R., Houle, S., Nilsson, L.-G., \& TulVING, E. (1996). Activation of medial temporal structures during episodic memory retrieval. Nature, 380, 715-717.

Paulesu, E., Frith, C. D., \& Frackowiack, R. S. J. (1993). The neural correlates of the verbal component of working memory. Nature, $\mathbf{3 6 2}$. 342-354.

RaJARAM, S. (1993). Remembering and knowing: Two means of access to the personal past. Memory \& Cognition, 21, 89-102.

Rankin, J. S., \& Kausler, D. H. (1979). Adult age differences in false recognitions. Journal of Gerontologv, 34, 58-65.

READ, J. D. (1996). From a passing thought to a false memory in $2 \mathrm{~min}$ utes: Confusing real and illusory events. Psychonomic Bulletin \& Review. 3, 105-111.

RoEDIGER, H. L., III (1996). Memory illusions. Journal of Memory \& Language, 35, 76-100

RoediGer, H. L., III, \& MCDermotT, K. B. (1995). Creating false memories: Remembering words not presented in lists. Journal of Experimental Psychology: Learning, Memory: \& Cognition. 21, 803-814

Russell, W. A., \& Jenkins, J. J. (1954). The complete Minnesota 
norms for responses to 100 words from the Kent-Rosanoff Word Association Test (Tech. Rep. No. 11, Contract N8 ONR 66216, Office of Naval Research). University of Minnesota.

SCHACTER, D. L. (1995). Memory distortion: History and current status. In D. L. Schacter, J. T. Coyle, G. D. Fischbach, M.-M. Mesulam, \& L. E. Sullivan (Eds.), Memory distortion: How minds, brains and societies reconstruct the past (pp. 1-43). Cambridge, MA: Harvard University Press.

SCHACTER, D. L. (1996). Searching for memory: The brain, the mind, and the past. New York: Basic Books.

Schacter, D. L., Alpert, N. M., Savage, C. R., Rauch, S. L., \& ALBERT, M. S. (1996). Conscious recollection and the human hippocampal formation: Evidence from positron emission tomography. Proceedings of the National Academy of Sciences, 93, 321-325.

Schacter, D. L., Curran, T., Galluccio, L., Milberg, W., \& BATES, J. (1996). False recognition and the right frontal lobe: A case study. Neuropsychologia, 34, 793-808.

Schacter, D. L., Reiman, E., Curran, T., Yun, L. S., Bandy, D., McDermotT, K. B., \& Roediger, H. L., III (1996). Neuroanatomical correlates of veridical and illusory recognition memory revealed by PET. Neuron, 17, 267-274.

Schacter, D. L., Reiman, E., Uecker, A., Polster, M. R., Yun, L. S., \& COOPER, L. A. (1995). Brain regions associated with retrieval of structurally coherent visual information. Nature, 376, 587-590.

Schacter, D. L., Savage, C. R., Alpert, N. M., Rauch, S. L., \& AlBERT, M. S. (1996). The role of hippocampus and frontal cortex in agerelated memory changes: A PET study. NeuroReport, 7, 1165-1169.

Schacter, D. L., Verfaellie, M., \& Pradere, D. (1996). The neuropsychology of memory illusions: False recall and recognition in amnesic patients. Journal of Memory \& Language, 35, 319-334.

Schooler, J. W., Gerhard, D., \& Lofrus, E. F. (1986). Qualities of the unreal. Journal of Experimental Psychology: Learning, Memorv, \& Cognition, 12, 171-181.

Shimamura, A. P. (1995). Memory and frontal lobe function. In M. Gazzaniga (Ed.), The cognitive neurosciences (pp. 803-813). Cambridge, MA: MIT Press.

Squire, L. R., Ojemann, J. G., Miezin, F. M., Petersen, S. E., Videen, T. O., \& RaIchle, M. E. (1992). Activation of the hippocampus in normal humans: A functional anatomical study of memory. Proceedings of the National Academy of Sciences, 89, 1837-1841.

Stuss, D. T., Eskes, G. A., \& FosteR, J. K. (1994). Experimental neuropsychological studies of frontal lobe functions. In F. Boller \& J. Grafman (Eds.), Handbook of neuropsychology (Vol. 9, pp. 149-185). Amsterdam: Elsevier.

Sulin, R. A., \& Dooling, D. J. (1974). Intrusion of a thematic idea in the retention of prose. Journal of Experimental Psychology, 103, 255-262.

Tulving, E. (1985). Memory and consciousness. Canadian Psychologist, 26, 1-12.

Tun, P. A., Wingfield, A., Blanchard, L., \& Rosen, M. (1996, April). Older adults show greater false recognition effects than young adults. Paper presented at the Cognitive Aging Conference, Atlanta, GA.

Tun, P. A., Wingfield, A., \& Rosen, M. J. (1995, November). Age effects on false memory for words. Paper presented at the meeting of the Psychonomic Society, Los Angeles.

UNDERWOOD, B. J. (1965). False recognition produced by implicit verbal responses. Journal of Experimental Psychology, 70, 122-129.

ZARAGOZA, M. S., \& LANE, S. M. (1994). Source misattributions and the suggestibility of eyewitness memory. Journal of Experimental Psychology: Learning, Memory, \& Cognition, 20, 934-945.

(Manuscript received March 12, 1996; revision accepted for publication August 22, 1996.) 